\title{
CARACTERIZAÇÃO FENOTÍPICA E GENOTÍPICA DE PROGÊNIES DE Euterpe oleracea COLETADOS NO AFUÁ-PARÁ NAS CONDIÇÕES DO AMAPÁ
}

\author{
Gilberto Ken-Iti Yokomizo', José Antônio Leite de Queiroz², Emanuel da Silva Cavalcante³, \\ Izaque de Nazaré Pinheiro ${ }^{4}$, Paulo André Rodrigues da Silva ${ }^{5}$, Silas Mochiutti
}

(recebido: 14 de junho de 2010; aceito: 22 de dezembro de 2011)

\begin{abstract}
RESUMO: O fruto do açaizeiro (Euterpe oleracea) é uma das principais fontes alimentares nos Estados do Pará e Amapá, despertando interesse de consumo em outras regiões e países. Por esse motivo, foram avaliadas 75 progênies coletadas de diferentes populações oriundas do Afuá, Estado do Pará, cultivadas no Campo Experimental de Mazagão, Estado do Amapá, em relação a caracteres vegetativos que possam resultar em melhor desenvolvimento da planta e refletir em maiores produções. O delineamento adotado foi o de blocos ao acaso com duas repetições. Os resultados permitem concluir que existem diferenças entre as progênies para a quantidade de brotações, porém, ao atingir a maturidade há um processo natural em que essas diferenças são eliminadas nas plantas adultas, indicando haver maior variabilidade nas plantas jovens que nas adultas; a relação $\mathrm{CVg} / \mathrm{CVe}$ e os valores de herdabilidade mostram que a seleção pode ser dificultada; as correlações confirmam que deve ser desenvolvido e realizado o manejo de perfilhos (jovens e rebentos), em decorrência da tendência de efeitos negativos destes sobre os demais caracteres; os valores estimados de correlações fenotípicas, genotípicas e residuais demonstram que os fatores ambientais contribuem para a variabilidade da espécie e a análise de agrupamento permitiu a formação de grupos dissimilares úteis para orientar futuros cruzamentos.
\end{abstract}

Palavras-chave: Açaizeiro, desenvolvimento sustentável da Amazônia, melhoramento genético, parâmetros genéticos, teste de progênies.

\section{PHENOTYPIC AND GENOTYPIC CHARACTERIZATION OF Euterpe oleracea PROGENIES COLLECTED FROM AFUÁ-PARÁ IN THE AMAPÁ CONDITIONS}

\begin{abstract}
The assai tree fruits (Euterpe oleracea) is one of the main food sources in the States of Pará and Amapá, generating consumer interest in other regions and countries. In this research were evaluated 75 progenies collected from different populations derived from Afuá, Pará, cultivating an Mazagão experimental field in Amapa State, in relation to vegetative characters that can result in better plant development and reflect on larger yield. The experimental design adopted was randomized blocks with two replications. The results indicate that there are differences among the progeny for the amount of shoots to reach maturity is a natural process in which these differences become less pronounced in adult plants, indicating greater variability in the young than in adult plants; the relationship $\mathrm{CVg} / \mathrm{CVe}$ and the heritability values show that the selection may be difficult; the correlations confirm that should be developed and implementd the management of stems (sprouts shoots) due to the tendency of these negative effects on other traits; The estimated phenotypic, genotypic and residural correlations show that environmental factors contribute to the variability of the species and cluster analysis allowed the formation of dissimilar groups useful for guiding future crosses.
\end{abstract}

Key words: Assai tree fruits, sustainable development of the Amazon, genetic breeding, genetics parameters, progeny test.

\section{INTRODUÇÃO}

Euterpe oleracea Mart., conhecida como açaizeiro, é uma espécie nativa da Região Amazônica encontrada nas várzeas do estuário, com seu fruto, o açaí, possuindo inestimável importância socioeconômica nos Estados do Pará e do Amapá por constituir uma das principais fontes alimentares dos ribeirinhos e nas cidades.
Sua composição é caracterizada por um elevado teor de lipídios, proteínas, fibras e antocianinas. Na região Sul do Brasil, o consumo é crescente, tendo como atrativos o fato de ser um alimento com apelo ecológico, oriundo da região amazônica, e energético (ROGEZ, 2000). Essas características interessantes sugerem prognósticos de crescimento de exportação da polpa de açaí, inclusive para os mercados de elevado poder aquisitivo do Hemisfério Norte.

\footnotetext{
${ }^{1}$ Engenheiro Agrônomo, Pesquisador Doutor em Agronomia - Embrapa Amapá - Rod. JK, km 05 - Cx. P. 10 - 68903-970 - Macapá, AP, Brasil gilberto@cpafap.embrapa.br

${ }^{2}$ Engenheiro Florestal, Pesquisador Doutor em Engenharia Florestal - Embrapa Amapá - Rod. JK, km 05 - Cx. P. 10 - 68903-970 - Macapá, AP, Brasil-1eite@cpafap.embrapa.br, silas.mochiutti@cpafap.embrapa.br

${ }^{3}$ Engenheiro Agrônomo, Pesquisador Mestre em Agronomia - Embrapa Amapá - Rod. JK, km 05 - Cx. P. 10 - 68903-970 - Macapá, AP, Brasil emanuel@cpafap.embrapa.br

${ }^{4}$ Geógrafo - Embrapa Amapá - Rod. JK, km 05 - Cx. P. 10 - 68903-970 - Macapá, AP, Brasil - izaque@cpafap.embrapa.br

${ }^{5}$ Técnico Agrícola - Embrapa Amapá - Rod. JK, km 05 - Cx. P. 10 - 68903-970 - Macapá, AP, Brasil - paulo.andre@cpafap.embrapa.br
}

Cerne, Lavras, v. 18, n. 2, p. 205-213, abr./jun. 2012 
O aumento do consumo tem motivado a implantação do cultivo de açaizais em terra firme e desenvolvimento de sistemas de manejo (QUEIROZ; MOCHIUTTI, 2001). Entretanto, essa expansão tem apresentado resultados heterogêneos de produtividade e qualidade dos frutos, existindo apenas um material selecionado pela Embrapa Trópico Úmido (Belém) denominada de BRS Pará.

Para o melhoramento da espécie tem se observado a presença de diferenças genéticas entre populações e/ou progênies em diversos caracteres, indicando a possibilidade na seleção de materiais superiores em açaizeiro (FARIAS NETO et al., 2003; OHASHI; KAGEYAMA, 2004; OLIVEIRA et al., 2000).

Porém, uma característica inerente do pouco tempo do processo de domesticação do açaizeiro em comparação com outras espécies consideradas tradicionais, como a soja, o milho, o arroz e a mandioca é a existência de poucos resultados apresentados em artigos científicos, tornando importante todas as pesquisas envolvendo esta espécie.

Conduziu-se este trabalho, com o objetivo de avaliar a variabilidade fenotípica e genotípica de progênies de açaizeiros originadas de populações existentes no município de Afuá, pertencente ao Estado do Pará em relação a caracteres vegetativos, estimar as correlações fenotípicas e genotípicas e analisar a potencialidade da população como material genético a ser utilizado no melhoramento da espécie.

\section{MATERIAL E MÉTODOS}

Setenta e cinco progênies de Euterpe oleracea originárias de populações existentes nas proximidades do município de Afuá (Pará), foram avaliadas no Campo Experimental de Mazagão, Estado do Amapá, pertencente a Embrapa Amapá, em área de várzea cujo solo predominante é do tipo Gley Pouco Húmico de textura média, drenado e de fertilidade média-alta. As progênies apresentavam seis anos de idade no momento de avaliação. A área experimental localiza-se nas coordenadas $00^{\circ} 02^{\prime} 33^{\prime \prime}$ de latitude sul e $51^{\circ} 15^{\prime} 24^{\prime \prime}$ longitude oeste, a $15 \mathrm{~m}$ altitude, apresentando topografia plana e cobertura vegetal tipo capoeira. Apresenta tipo climático Ami, segundo a classificação de Köppen, caracterizando-se por ser tropical chuvoso, com temperatura média do mês mais frio não inferior a $22,5^{\circ} \mathrm{C}$ e com precipitação do mês mais seco de $10 \mathrm{~mm}$. O regime climático apresenta precipitação média anual de $2.300 \mathrm{~mm}$, havendo concentração entre os meses de janeiro a junho, sendo a temperatura média anual de $28^{\circ} \mathrm{C}$ e umidade média do ar de $85 \%$.

Cerne, Lavras, v. 18, n. 2, p. 205-213, abr./jun. 2012
O delineamento experimental utilizado foi o de blocos ao acaso com duas repetições e para cada repetição foi utilizada a média de até cinco plantas úteis por parcela. $\mathrm{O}$ espaçamento entre plantas foi de $4 \mathrm{~m} \times 5 \mathrm{~m}$ (500 plantas/ha).

Foram avaliados os seguintes caracteres adaptados com base na nomenclatura proposta por Oliveira et al. (2006): QTA: quantidade de estipes adultas com vestígios ou presença de frutificação presente na touceira; QTJ: quantidade de estipes jovens próximas da frutificação, mas sem presença de vestígios de frutificação anterior presentes na touceira; QTR: quantidade de estipes com menos de 1,50m de altura presentes na touceira; APA: altura de uma planta adulta representativa da média das adultas presentes na touceira, medida em metros; APJ: altura de uma planta jovem representativa da média das jovens presentes na touceira, medida em metros; CAP: circunferência do estipe mais velho da touceira a altura do peito, medida em centímetros na altura de $1,30 \mathrm{~m}$ a partir do solo; CAJ: circunferência da estipe representativa da média das estipes jovens da touceira a altura do peito, medida em centímetros na altura de 1,30m a partir do solo; NTC: número de cachos produzidos durante os anos de produção, pela contagem de cicatrizes indicativas de desenvolvimento de cachos em anos anteriores; CEN: comprimento do entrenó medido à altura do peito, em centímetros e; NF: quantidade de folhas existente na estipe mais velha da touceira.

A análise de variância foi realizada com o intuito de estimar parâmetros fenotípicos e genotípicos e detectar eventuais diferenças entre tratamentos, também foram estimadas as correlações fenotípicas e genotípicas entre caracteres, além da herdabilidade, no sentido amplo pela relação entre as variâncias genotípicas e fenotípicas.

O modelo estatístico adotado para a análise de variância foi $Y i j=m+G i+R j+$ eij; em que: Yije é o valor fenotípico médio do caráter Y medido no material genético i, na repetição j; m é a média geral paramétrica dos dados em estudo; Gi é o efeito do i-ésimo genótipo, aleatório; Rj é o efeito da j-ésima repetição; eij é o erro médio associado à observação Yij, aleatório (VENCOVSKY; BARRIGA, 1992).

Considerou-se como aleatório o efeito de progênies ou genótipos, pois os materiais foram obtidos de polinização aberta entre as diversas plantas matrizes, sendo representativas da população sob estudo.

A análise de agrupamento foi feita, adotando-se a distância generalizada de Mahalanobis $\left(\mathrm{D}^{2}\right)$ como medida de dissimilaridade, por considerar a correlação entre os caracteres avaliados, segundo Cruz et al. (2004). Com 
base na matriz de dissimilaridade gerada, foi elaborado dendrograma pelo método de UPGMA (Unweighted Pair Group Method with Arithmetic Mean). O critério utilizado para a formação dos grupos é a média das distâncias entre todos os pares de itens que formam cada grupo. Sendo utilizado o programa GENES (CRUZ, 2001) para todas as análises.

\section{RESULTADOS E DISCUSSÃO}

Apenas os caracteres QTJ, QTR, CEN apresentaram diferenças significativas entre as progênies (Tabela 1), indicando haver variabilidade fenotípica e a possibilidade de existência de materiais superiores, similar para ao observado por Farias Neto et al. (2005). Esse resultado é importante, pois as progênies sem perfilhos (somatória de estipes jovens e rebentos) ou com máximo de quatro, geralmente apresentam baixa renovação da touceira e problemas posteriores de produção com seu envelhecimento. Já, as plantas que apresentam acima de oito perfilhos geram excessiva demanda de mão de obra para realizar a condução das touceiras, desta forma, o quantitativo ideal para manejo está entre quatro e oito perfilhos. Para o caráter CEN desejam-se valores menores, pois representa plantas que irão crescer menos em altura anualmente, facilitando o processo de colheita dos cachos de frutos em estipes com idades mais avançadas, prolongando com isso sua vida útil.

Para os caracteres QTA, CAP, CAJ, NTC, APA, APJ e NF houve ausência de diferenças significativas, sendo que os três últimos comportaram-se de forma semelhante ao obtido por Farias Neto et al. (2005). Isso indica que existe pouca variabilidade em estipes adultas para seu quantitativo na touceira, crescimento em altura e circunferência, além da quantidade de folhas. Para a altura seria desejável encontrar materiais mais baixos, visando a facilitar o processo de colheita dos cachos e com maiores circunferências, por permitir maior sustentabilidade da planta e de seus cachos. Além disso, o número de cachos também não apresentou variações, indicando que há constância, nesse caráter, mesmo entre plantas diferentes.

As médias gerais demonstram que as touceiras são compostas por maior quantidade de rebentos, seguido por estipes jovens e em menor quantidade aparecem as estipes adultas, dessa forma, existe alto potencial de renovação de plantas. Comparativamente, as touceiras apresentaram menor quantidade de estipes nas diferentes fases de desenvolvimento em relação aos observado por Oliveira et al. (2007). Diferenças oriundas provavelmente decorrente das características específicas das populações base e também das condições edafo-climáticas das áreas experimentais serem diferentes.

Para o caráter CEN, NF, CAP e CAJ, os valores obtidos foram próximos aos observados por Oliveira et al. (2007), indicando que esses caracteres não apresentam muita variação entre diferentes populações. Ressaltando que para CEN são desejados valores menores, pois as plantas apresentam menor crescimento em altura, facilitando a colheita dos cachos de frutos.

$\mathrm{O}$ coeficiente de variação experimental (CV), envolvendo a quantidade de indivíduos adultos, jovens e rebentos foi alta, demonstrando haver elevada variabilidade entre as diferente progênies. Interessante é que existe uma diminuição do $\mathrm{CV}$, conforme há aumento de idade das estipes na touceira, indicando tendência de estabilização

Tabela 1 - Resumo da análise de variância para progênies de Euterpe oleracea originadas do município de Afuá - Pará.

Table 1 - Variance analysis summary for Euterpe oleracea progenies originated of the municipality of Afuá - Pará.

\begin{tabular}{lcccccccccccc}
\hline FV & GL & QTA & QTJ & QTR & APA & APJ & CAP & CAJ & NTC & CEN & NF \\
\hline Blocos & 1 & 3,29 & 0,90 & 0,87 & 9,46 & 5,03 & 409,40 & 26,13 & 2,18 & 34,07 & 12,16 \\
Progênies & 74 & $0,19^{\text {ns }}$ & $0,77^{*}$ & $2,06^{* *}$ & $0,85^{\text {ns }}$ & $0,41^{\text {ns }}$ & $27,04^{\text {ns }}$ & $8,57^{\text {ns }}$ & $0,88^{\text {ns }}$ & $3,71^{* *}$ & $0,77^{\text {ns }}$ \\
Resíduo & 74 & 0,23 & 0,45 & 0,99 & 0,66 & 0,33 & 19,02 & 9,20 & 1,02 & 2,07 & 0,72 \\
Média & & 1,08 & 1,20 & 1,59 & 5,91 & 3,12 & 36,07 & 23,44 & 3,90 & 13,18 & 10,54 \\
CV $(\%)$ & & 44,56 & 55,71 & 62,63 & 13,71 & 18,53 & 12,09 & 12,94 & 25,94 & 10,93 & 8,05 \\
\hline
\end{tabular}

** e *: significativos a 1 e $5 \%$ de probabilidade, respectivamente, pelo teste $\mathrm{F}$; ns: não-significativo, pelo teste $\mathrm{F}$ QTA: quantidade de estipes adultas; QTJ: quantidade de estipes jovens; QTR: quantidade de estipes imaturas; APA: altura de planta adulta; APJ: altura de planta jovem; CAP: circunferência do estipe mais velho a altura do peito; CAJ: circunferência do estipe jovem a altura do peito; NTC: cachos produzidos durante os anos de produção; CEN: comprimento do entrenó medido na altura do peito e; NF: quantidade de folhas existente na estipe mais velha da touceira.

Cerne, Lavras, v. 18, n. 2, p. 205-213, abr./jun. 2012 
em estipes mais velhas. Os caracteres QTA, APA, NF e CAP comportaram-se de forma semelhante ao obtido por Oliveira et al. (2007), demonstrando que nas estipes adultas existe similaridade entre as populações avaliadas, enquanto que nos demais caracteres relativos a quantidade na touceira os resultados obtidos foram superiores.

Observa-se contribuições superiores das variâncias residuais em relação as genotípicas (Tabela 2). Esse tipo de comportamento gera dificuldades de se obter resultados satisfatórios originados pelos fatores genéticos, por depender diretamente das condições ambientais em que sejam testadas as progênies. Comportamento semelhante ao observado por Farias Neto et al. (2007), cujas variâncias residuais foram superiores que as genéticas.

As estimativas de herdabilidade (Tabela 2) apresentaram valores que permitem a seleção nos caracteres QTJ, QTR e CEN, porém abaixo do obtido por Farias Neto et al. (2005) de 62,42\% para a quantidade de perfilhos. Esses valores demonstram haver probabilidade média de que essas características sejam transferidas para seus descendentes oriundos de seleção e, com isso, manifestar um quantitativo adequado de perfilhos e comprimento de entrenó, facilitando o manejo e permitindo uma vida útil mais longa das touceiras. Os demais caracteres, ao contrário, indicaram dificuldades de transferência para seus descendentes.

$\mathrm{O}$ valor obtido para o caráter $\mathrm{CEN}$ foi pouco abaixo do obtido por Farias Neto et al. (2007), enquanto que comportamento similar foi observado para altura de plantas adultas e número de folhas viáveis. Já, para a altura de plantas jovens, esse valor ficou bem próximo do observado por Farias Neto et al. (2007), devendo-se, nas próximas pesquisas, determinar quais os principais fatores ambientais que possam influenciar diretamente esses caracteres e como buscar a minimização desses efeitos.

Um índice que serve como indicativo da facilidade em se realizar a seleção e obter resultados é a relação entre o coeficiente de variação genético e o residual, sendo que valores próximos ou acima da unidade demonstram grande chance em se obter sucesso com menores esforços. A relação $\mathrm{CVg} / \mathrm{CVe}$ apresentou como promissores os caracteres QTJ, QTR e CEN (Tabela 2), sendo que os dois primeiros caracteres são relativos à quantidade de perfilhos, porém esses valores foram menores que o obtido para número de perfilhos por Farias Neto et al. (2005). Nos demais caracteres houve indicação de dificuldade em se selecionar os melhores materiais, pois grande contribuição no fenótipo do que foi observado teve influência ambiental e não genética. Esse comportamento foi semelhante ao observado por Oliveira e Fernandes (2001). Para QTA, CAJ e NTC, a presença de elevados efeitos ambientais, totalizando grande porcentagem da variância, tornou os valores da genética irrelevantes.

$\mathrm{O}$ coeficiente de variação genética $(\mathrm{CVg})$ foi baixo para os caracteres APA, APJ, CAP, CEN e NF, demonstrando que esses caracteres apresentam pouca contribuição genética aditiva, com amplitude de valores próximos aos obtidos por Farias Neto et al. (2007), enquanto que QTJ e QTR apresentaram valores que indicam possibilidade de obter resultados na seleção, possuindo variabilidade genética potencial.

Tabela 2 - Parâmetros genéticos e ambientais da análise conjunta em relação aos caracteres, envolvendo 75 progênies de Euterpe oleracea originadas do município de Afuá - Pará.

Table 2 - Genetic and environmetals parameters of the joint analysis in relation to the characters, involving 75 Euterpe oleracea progenies originated of the municipality of Afú - Pará.

\begin{tabular}{lcrrrrrrrrr}
\hline Parameters & QTA & QTJ & QTR & APA & APJ & CAP & CAJ & NTC & CEN & NF \\
\hline CVg(\%) & - & 33,49 & 45,96 & 5,31 & 6,11 & 5,55 & - & - & 6,87 & 1,55 \\
CVg/Cve & - & 0,60 & 0,73 & 0,39 & 0,33 & 0,46 & - & - & 0,63 & 0,19 \\
Var.genética & - & 0,16 & 0,53 & 0,10 & 0,04 & 4,01 & - & - & 0,82 & 0,03 \\
Var.ambiental & 0,23 & 0,45 & 0,99 & 0,66 & 0,33 & 19,02 & 9,20 & 1,02 & 2,07 & 0,72 \\
H(\%) & - & 41,96 & 51,86 & 23,09 & 17,84 & 29,65 & - & - & 44,17 & 6,92 \\
\hline
\end{tabular}

Caselas vazias: valores não estimados;

QTA: quantidade de estipes adultas; QTJ: quantidade de estipes jovens; QTR: quantidade de estipes imaturas; APA: altura de planta adulta; APJ: altura de planta jovem; CAP: circunferência do estipe mais velho a altura do peito; CAJ: circunferência do estipe jovem a altura do peito; NTC: cachos produzidos durante os anos de produção; CEN: comprimento do entrenó medido na altura do peito e; NF: quantidade de folhas existente na estipe mais velha da touceira.

Cerne, Lavras, v. 18, n. 2, p. 205-213, abr./jun. 2012 
Os caracteres QTA, CAJ e $\mathrm{NC}$, em razão da elevada contribuição ambiental, não apresentaram $\mathrm{CVg}$ significativos, sendo que comportamentos semelhantes foram obtidos por Farias Neto et al. $(2005,2007)$. De forma geral, com base na relação $\mathrm{CVg} / \mathrm{CVe}$ e valores de herdabilidade, o processo de seleção em todos os caracteres citados pode apresentar dificuldade nas condições do experimento.

Segundo Cohen (1988), os limites das classes nas correlações, geralmente são adotados de forma subjetiva e devem ser flexíveis, dependendo do contexto e do propósito da pesquisa. Em razão do material avaliado encontrar-se no início de domesticação, portanto sem seleção, optou-se por utilizar limites mais amplos. Dessa forma, a escala adotada baseou-se nos trabalhos de Cohen (1988) e Santos (2007), sendo considerada as correlações com valores entre 0 a $29 \%$ como baixas, entre 30 a $49 \%$ como médias e entre 50 a $100 \%$ como altas.

Algumas estimativas de correlações genotípicas não foram possíveis de serem calculadas, pela elevada predominância dos efeitos ambientais (Tabela 3). As correlações foram, em geral, baixas a médias entre os caracteres relacionados ao crescimento das estipes com QTJ e QTR. Foi observada também tendência de diminuições dos caracteres de desenvolvimento vegetativo com aumento de QTJ, principalmente pela presença de correlações negativas. Devendo-se, nesse caso, buscar um equilíbrio entre altura das estipes com número adequado das mesmas, pois, possivelmente, as progênies com menores alturas, que são as mais desejadas, apresentem número muito elevado de perfilhos jovens, dificultando o manejo da touceira.

Para o caráter NF, observou-se a presença de correlações baixas e médias com os demais caracteres, portanto pode ser considerado um caráter com expressão fenotípica praticamente independente dos demais caracteres. Apresentando apenas uma correlação alta, porém negativa com QTR, em razão de o sombreamento causar inibição no brotamento dos rebentos.

A correlação foi positiva e alta entre os caracteres CAP e CEN, indicativo que um caráter tende a ter seu valor aumentado com a elevação do outro e vice-versa, por estarem diretamente relacionados com as dimensões finais que a planta poderá apresentar, nesse caso plantas com maiores circunferências apresentam tendência de maiores comprimentos do entrenó, o que é indesejável, pois o desejável são plantas mais baixas para facilitar a colheita, porém com maior circunferência para garantir o suporte adequado dos cachos e da própria touceira.
Os valores estimados de correlações fenotípicas, genotípicas e residuais demonstram que os fatores ambientais contribuem para a variabilidade da espécie. Esse fato é problemático para fins de seleção, pois há indicativos da necessidade de se testar os materiais nos novos ambientes, toda vez que houver introdução destes em novas localidades.

Um fato interessante é que QTR e QTJ apresentaram tendência de correlações negativas com determinados caracteres vegetativos, indicando que a prática do manejo de perfilhos deve ser adotada quando se deseja um desenvolvimento adequado e vigoroso das plantas, de modo a permitir o desenvolvimento adequado das estipes associado com um número adequado de perfilhos, confirmando a afirmação de Calzavara (1972).

Visando a estudar o comportamento das progênies em termos de agrupamentos foi estruturado um dendograma. Conforme Cruz et al. (2004), a formação dos grupos é realizada de forma subjetiva, tendo como base as mudanças acentuadas de níveis e também na característica de não ter ocorrido processo de seleção no material. Os limites adotados para a formação de grupos neste trabalho foram $100 \%$ de dissimilaridade e a média das medidas de dissimilaridade (50\%). Sendo que o método utilizado foi o UPGMA(Unweighted Pair Group Method with Arithmetic Mean), cujo critério utilizado para a formação dos grupos é a média das distâncias entre todos os pares de itens que formam cada grupo. Em termos de melhoramento genético, Dudley (1994) refere-se ao método UPGMA como superior aos métodos do vizinho mais próximo e mais distante.

No dendograma (Figura 1), com a adoção do primeiro limite (100\% de dissimilaridade) foi possível a visualização de três grupos (A, B e C), sendo o grupo $\mathrm{C}$ mais dissimilar e contendo menor quantidade de progênies.

No limite de $50 \%$ de dissimilaridade, foi possível observar a formação de sete grupos, sendo compostos por um máximo de 18 progênies e um mínimo de 6 , havendo um desdobramento equitativo em relação aos três grupos observados no limite de $100 \%$, com a divisão em três ou dois novos subgrupos. A composição aparentemente equitativa é interessante num banco ativo de germoplasma. Indicativo que a coleta realizada do germoplasma conseguiu capturar genótipos divergentes, capturando o máximo de diversidade possível e retendo, com isso, variabilidade no BAG. Distribuição similar ao observado por Oliveira et al. (2007).

Cerne, Lavras, v. 18, n. 2, p. 205-213, abr./jun. 2012 
Tabela 3 - Correlações fenotípicas, genotípicas e residuais em 10 caracteres envolvendo 75 progênies de açaizeiros Euterpe oleracea originadas do município de Afuá - Pará.

Table 3 - Phenotypic, genotypic and residual correlations in 10 characters involving 75 Euterpe oleracea progenies originated of the municipality of Afuá - Pará.

\begin{tabular}{|c|c|c|c|c|c|c|c|c|c|}
\hline & QTJ & QTR & APA & APJ & CAP & CAJ & NTC & CEN & NF \\
\hline & $11,24^{\mathrm{ns}}$ & $8,13^{\text {ns }}$ & $47,95 *$ & $29,07 *$ & $45,31 *$ & $5,40^{\text {ns }}$ & $29,47 *$ & $37,82 *$ & $40,62 *$ \\
\hline \multirow[t]{3}{*}{ QTA } & - & - & - & - & - & - & - & - & - \\
\hline & $19,11^{n s}$ & $-9,81^{n s}$ & $26,56^{*}$ & $11,89^{n s}$ & $20,48^{n s}$ & $-15,55^{n s}$ & $30,78 *$ & $34,43 *$ & $52,51 *$ \\
\hline & & $66,64 *$ & $13,25^{\mathrm{ns}}$ & $7,59^{\mathrm{ns}}$ & $9,00^{\text {ns }}$ & $-11,13^{\mathrm{ns}}$ & $-21,89^{\mathrm{ns}}$ & $11,81^{\mathrm{ns}}$ & $-10,41^{\mathrm{ns}}$ \\
\hline \multirow[t]{3}{*}{ QTJ } & & 82,80 * & $-9,85^{\text {ns }}$ & $8,58^{\text {ns }}$ & $-7,38^{\text {ns }}$ & - & - & $-22,20^{\mathrm{ns}}$ & - \\
\hline & & $53,00^{*}$ & $24,42 *$ & $7,59^{n s}$ & $18,16^{n s}$ & $-13,41^{n s}$ & $-6,80^{n s}$ & $37,54 *$ & $11,84^{n s}$ \\
\hline & & & $-3,17^{\mathrm{ns}}$ & $-8,36^{\text {ns }}$ & $-6,24^{\mathrm{ns}}$ & $-16,70^{\mathrm{ns}}$ & $-27,41 *$ & $4,59^{\mathrm{ns}}$ & $-18,52^{\mathrm{ns}}$ \\
\hline \multirow[t]{3}{*}{ QTR } & & & $-16,13^{\text {ns }}$ & $-43,24 *$ & $-18,37^{\mathrm{ns}}$ & - & - & $-11,33^{\text {ns }}$ & $-62,68 *$ \\
\hline & & & $3,97^{n s}$ & $7,63^{n s}$ & $1,66^{n s}$ & $7,22^{n s}$ & $-25,05 *$ & $19,31^{n s}$ & $-9,93^{n s}$ \\
\hline & & & & $54,20 *$ & $88,57^{*}$ & $31,81^{*}$ & $24,88 *$ & $65,69 *$ & $48,11 *$ \\
\hline \multirow[t]{3}{*}{ APA } & & & & $70,99 *$ & $88,67 *$ & - & - & $83,76 *$ & $-11,45^{\mathrm{ns}}$ \\
\hline & & & & $50,06 *$ & $88,87 *$ & $25,12 *$ & $44,94 *$ & $59,43 *$ & $58,57 *$ \\
\hline & & & & & $46,77 *$ & $75,92 *$ & $11,66^{\text {ns }}$ & $40,30 *$ & $26,71 *$ \\
\hline \multirow[t]{3}{*}{ APJ } & & & & & $25,55 *$ & - & - & $79,72 *$ & $-26,83$ * \\
\hline & & & & & $53,79 *$ & $70,06 *$ & $11,15^{n s}$ & $26,45 *$ & $33,95 *$ \\
\hline & & & & & & $29,80 *$ & $22,68^{\text {ns }}$ & $55,84 *$ & $48,08 *$ \\
\hline \multirow[t]{3}{*}{ CAP } & & & & & & - & - & $61,72 *$ & $49,49 *$ \\
\hline & & & & & & $35,22 *$ & $35,65 *$ & $53,46^{*}$ & $50,66 *$ \\
\hline & & & & & & & $2,47^{\mathrm{ns}}$ & $21,58^{\mathrm{ns}}$ & $17,62^{\mathrm{ns}}$ \\
\hline \multirow[t]{3}{*}{ CAJ } & & & & & & & - & - & - \\
\hline & & & & & & & $3,38^{n s}$ & $7,19^{n s}$ & $5,30^{n s}$ \\
\hline & & & & & & & & $22,03^{\mathrm{ns}}$ & $13,81^{\mathrm{ns}}$ \\
\hline \multirow[t]{3}{*}{ NTC } & & & & & & & & - & - \\
\hline & & & & & & & & $22,60^{n s}$ & $47,21 *$ \\
\hline & & & & & & & & & $11,88^{\mathrm{ns}}$ \\
\hline \multirow[t]{2}{*}{ CEN } & & & & & & & & & - \\
\hline & & & & & & & & & $43,52 *$ \\
\hline
\end{tabular}

*: significativo a $5 \%$ pelo teste $\mathrm{T}$

Em negrito: correlações genotípicas; em itálico: correlações residuais; caselas vazias: valores não estimados

QTA: quantidade de estipes adultas; QTJ: quantidade de estipes jovens; QTR: quantidade de estipes imaturas; APA: altura de planta adulta; APJ: altura de planta jovem; CAP: circunferência do estipe mais velho a altura do peito; CAJ: circunferência do estipe jovem a altura do peito; NTC: cachos produzidos durante os anos de produção; CEN: comprimento do entrenó medido na altura do peito e; NF: quantidade de folhas existente na estipe mais velha da touceira.

Cerne, Lavras, v. 18, n. 2, p. 205-213, abr./jun. 2012 


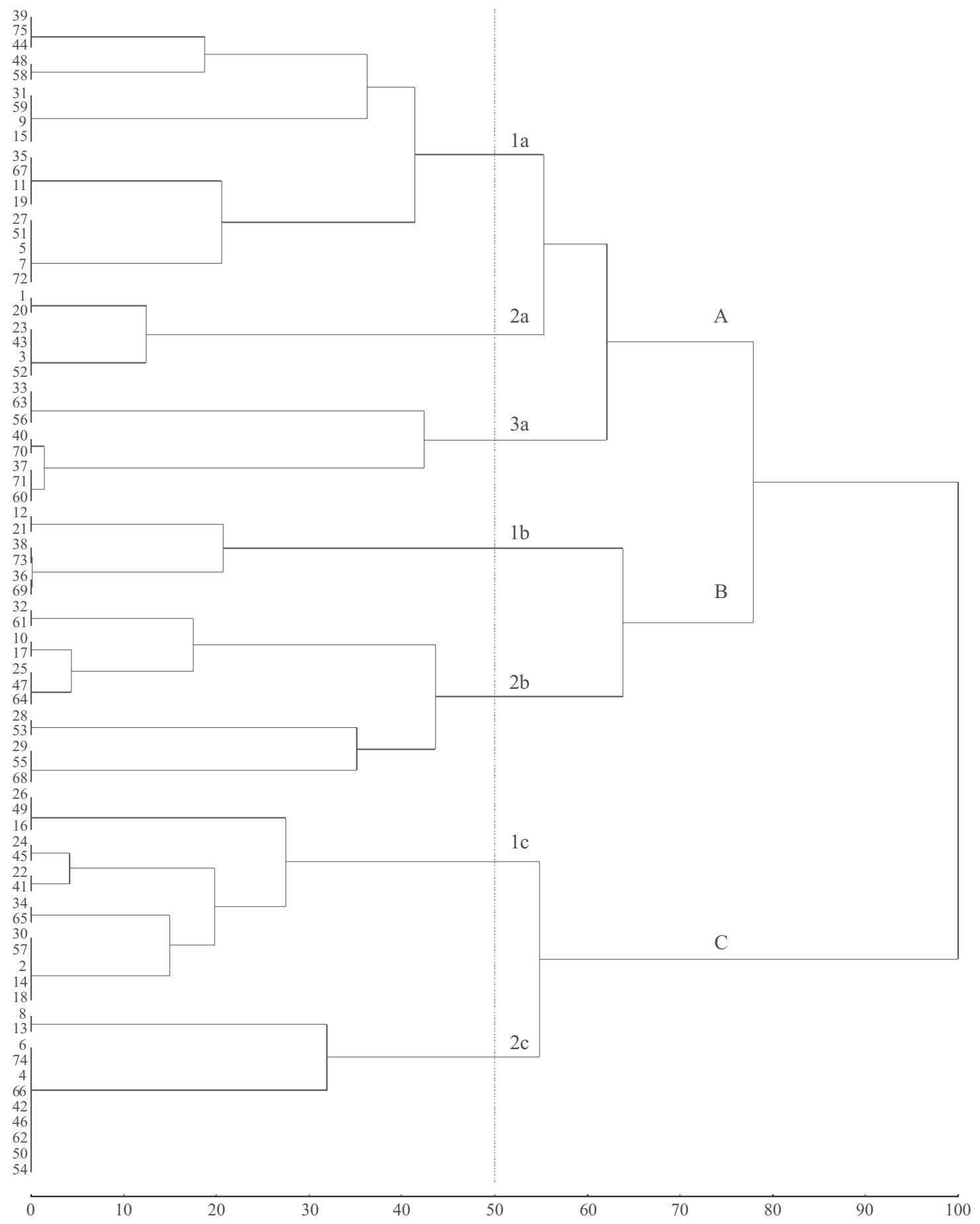

Figura 1 - Construção de uma árvore de distância usando o método de ligação média entre grupos (UPGMA) envolvendo 75 progênies de Euterpe oleracea com base em 10 caracteres morfológicos. Macapá, AP, 2008.

Figure 1 - Construction of a distance tree using clustering with Unweighted Pair Group Method with Arithmetic Mean (UPGMA) involving 75 Euterpe oleracea progenies with base in 10 morphologic characters. Macapá, AP, 2008.

Cerne, Lavras, v. 18, n. 2, p. 205-213, abr./jun. 2012 
$\mathrm{Na}$ formação dos grupos não houve padrão de distribuição biogeográfica linear e contígua das progênies na região de coleta, pois não ocorreu agrupamento em sequências numéricas. Além disso, a coleta permitiu manter a variabilidade fenotípica existente nas populações naturais, conferindo uma ampla variabilidade com base nos caracteres avaliados em conjunto, o que permitiu a formação dos grupos. Possivelmente, com o processo de seleção, essa plasticidade seja reduzida pelo processo de estreitamento da base genética. Esse fato também foi comentado e observado no trabalho realizado por Oliveira et al. (2007).

\section{CONCLUSÕES}

Existem diferenças entre as progênies para a quantidade de brotações, porém, ao atingir a maturidade, há um processo natural em que essas diferenças são eliminadas nas plantas adultas, indicando haver maior variabilidade nas plantas jovens que nas adultas.

A relação $\mathrm{CVg} / \mathrm{CVe}$ e os valores de herdabilidade mostram que a seleção pode ser dificultada.

As correlações confirmam que deve ser desenvolvido e realizado o manejo de perfilhos (jovens e rebentos) pela tendência de efeitos negativos destes sobre os demais caracteres.

Os valores estimados de correlações fenotípicas, genotípicas e residuais demonstram que os fatores ambientais contribuem para a variabilidade da espécie.

A análise de agrupamento permitiu a formação de grupos dissimilares úteis para orientar futuros cruzamentos.

\section{REFERÊNCIAS}

CALZAVARA, B. B. G. As possibilidades do açaizeiro no Estuário Amazônico. Boletim da Faculdade de Ciências Agrárias do Pará, Belém, v. 5, p. 1-103, 1972.

COHEN, J. Statistical power analysis for the behavioral sciences. Hillsdale Lawrence: Earlbaum, 1988. 567 p.

CRUZ, C. D. Programa genes: aplicativo computacional em genética e estatística. Viçosa, MG: UFV, 2001. 648 p.

CRUZ, C. D.; REGAZZI, A. J.; CARNEIRO, P. C. S. Modelos biométricos aplicados ao melhoramento genético. Viçosa, MG: UFV, 2004. 480 p.

DUDLEY, J. W. Comparison of genetic distance estimators using molecular marker data. In: SYMPOSIUM ANALYS OF
MOLECULAR DATA, 2., 1994, Corvallis. Proceedings... Corvallis: American Society for Horticultural Science; Crop Science Society of America, 1994. p. 3-7.

FARIAS NETO, J. T.; MULLER, A. A.; OLIVEIRA, M. S. P.; ESPÍRITO SANTO, D. E.; SILVA, M. A. Variabilidade genética entre duas procedências de açaizeiro (Euterpe oleracea Martus). Boletim de Pesquisa Florestal, Colombo, v. 46, p. 97-104, 2003.

FARIAS NETO, J. T.; OLIVERIA, M. S. P. de; MULLER, A. A.; NOGUEIRA, O. L.; ANAISSI, D. F. S. P. Variabilidade genética em progênies jovens de açaizeiro. Cerne, Lavras, v. 11, p. 336-341, 2005.

FARIAS NETO, J. T.; RESENDE, M. D. V. de; OLIVEIRA, M. S. P. de; SANTOS, N. S. A. dos; CANUTO, E. L.; NOGUEIRA, O. L.; MULLER, A. A. Avaliação genética de progênies de polinização aberta de açaí (Euterpe oleracea) e estimativas de parâmetros genéticos. Cerne, Lavras, v. 13, p. 376-383, 2007.

OHASHI, S. T.; KAGEYAMA, P. Y. Variabilidade genética entre populações de açaizeiro (Euterpe oleracea Mart.) do estuário amazônico. In: MOURÃO, L.; JARDIM, M. A.; GROSSMANN, M. (Ed.). Açaí: possibilidade e limites em processos de desenvolvimento sustentável no estuário amazônico. Belém: CEJUP, 2004. p. 11-26.

OLIVEIRA, M. S. P. de; FERNANDES, G. L. C.

Repetibilidade de caracteres do cacho de açaizeiro nas condições de Belém, PA. Revista Brasileira de Fruticultura, Jaboticabal, v. 23, p. 613-616, 2001.

OLIVEIRA, M. S. P. de; FERREIRA, D. F.; SANTOS, J. B. dos. Divergência genética entre acessos de açaizeiro fundamentada em descritores morfoagronômicos. Pesquisa Agropecuária Brasileira, Brasília, v. 42, p. 501-506, 2007.

OLIVEIRA, M. S. P. de; FERREIRA, D. F.; SANTOS, J. B. dos. Seleção de descritores para caracterização de germoplasma de açaizeiro para produção de frutos. Pesquisa Agropecuária Brasileira, Brasília, v. 41, p. 1133-1140, 2006.

OLIVEIRA, M. S. P. de; LEMOS, M. A.; SANTOS, V. F. dos; SANTOS, E. O. dos. Correlações fenotípicas entre caracteres vegetativos e de produção de frutos em açaizeiro. Revista Brasileira de Fruticultura, Jaboticabal, v. 22, p. 1-5, 2000.

Cerne, Lavras, v. 18, n. 2, p. 205-213, abr./jun. 2012 
QUEIROZ, J. A. L.; MOCHIUTTI, S. Plantio de açaizeiros. Macapá: Embrapa Amapá, 2001. 8 p. (Comunicado técnico, $55)$.

ROGEZ, H. Açaí: preparo, composição e melhoramento da conservação. Belém: Edufpa, 2000. 313 p.
SANTOS, C. Estatística descritiva: manual de autoaprendizagem. Lisboa: Edições Silabo, 2007. 264 p.

VENCOVSKY, R.; BARRIGA, P. Genética biométrica no fitomelhoramento. Ribeirão Preto: Sociedade Brasileira de Genética, 1992. 496 p.

Cerne, Lavras, v. 18, n. 2, p. 205-213, abr./jun. 2012 